\title{
Determination of the Soil Physco- Chemical Status of Itang Special Woreda Gambella Regional State
}

\author{
WASIHUN MENGISTE TAREKEGEN \\ WALGAK CHUOL BEL
}

\begin{abstract}
The study was conducted at the Achewa, Adong and Mekod district which is located in the Itang sprcial woreda of West of Gambella Regional state. The present study, therefore, is designed with The general objective of to determine of the soil physical and chemical status of the study area. With specific objective of to evaluate the fertility status of the soils in the study area and to identify the potentiality of land to grow crops. Field survey was carried out and Descriptive statistics were employed, finally with critical value were used to analyze the data. Soil samples were collected from three districts of Achewa, Adong and Mekod. Composite soil samples were taken from a depth of 0-20 cm representing these land uses and analyzed for selected soil physiochemical properties such as Texture,soil pH, electrical conductivity, Exchangeable Bases, CEC, Available P, Available K, Total N and Organic Carbon. The results showed that the soils texture in all land uses are clay loam except Mekod which was clay in texture and soil $\mathrm{pH}$ were neutral in Achewa and adong whereas alikaline in Mekod. The low soil $\mathrm{pH}$ in cultivated fields was probably due to continuous removal of basic cations by crops and intensive Achewa and Adong that enhanced leaching of basic cations. The bulk density and total porosity values of the study area are within the acceptable rang for agriculture inorganic soil. The OM content of the study area (1.51, 1.34 to 3.12\%), available $\mathrm{P}\left(13.72,11.35\right.$ and $\left.16.43 \mathrm{mg} \mathrm{kg}^{-1}\right)$ and total $\mathrm{N}(0.164,0.125$ and $0.245 \%)$ in Achewa, Adong and Mekod respectively. The soil exchange complex was mainly dominated by $\mathrm{Ca}$ and $\mathrm{Mg}$ where the order of occurrence was $\mathrm{Ca}>\mathrm{Mg}>\mathrm{K}>\mathrm{Na}$. The CEC values were very high ranging from 38, 45and cmol( + ) $\mathrm{kg}^{-1}$ in Achewa, Adong and Mekod respectively. The results of the study revealed that the physical and chemical properties of the soils are highly variable to each districts In general, special attention should be given to Achewa and Adong district to improve the soil fertility status of soils so as to sustain its productivity.
\end{abstract}

Keywords: determination, soil, physical, chemical

DOI: $10.7176 / \mathrm{JNSR} / 10-10-02$

Publication date:May $31^{\text {st }} 2020$

\section{INTRODUCTION}

Ethiopia, with a total area of 1.1 million $\mathrm{km}^{2}$, has a population of 72.4 million in 2004 out of which $85 \%$ are living rural. The rate of population growth is in the order of $3 \%$ per annum. The country has diverse topographic features which encompass high mountains, deep gorges, flat-topped plateaus, and rolling plains. The physical conditions and variations in altitude have resulted in a great diversity of climate, soil and vegetation (Asrat, 1992). Agriculture is the backbone of the economy engaging more than $85 \%$ of the population, accounting for nearly $52 \%$ of the country's gross domestic product (GDP) and for $90 \%$ of export earnings (FAO, 2005). The sector is dominated by subsistent smallholder farmers, which contribute $95 \%$ of the agricultural production, and pastorals with a nomadic form. The country also has the largest livestock population in Africa with untapped potential (Mengistu, 2002).

Soil fertility maintenance is a major concern in tropical Africa, particularly with the rapid population increase, which has occurred in the past few decades. In traditional farming systems, farmers use bush fallow, plant residues, household refuse, animal manures and other organic nutrient sources to maintain soil fertility and soil organic matter. Although this reliance on biological nutrient sources for soil fertility regeneration is adequate with low cropping intensity, it becomes unsustainable with more intensive cropping unless fertilizers are applied (Mulongey and Merck, 1993).

\subsection{Statement of the problem}

The present study involved soil fertility assessment of the soils at Itang special district in of the Gambella region. The research study area has not been carried out so far. Due to this reason lack of detail information on type and characteristics of soils of the research site has been a serious problem not only for proper implementation of the soil and water research activities, but also for reliable interpretation of the overall agricultural research findings. In light of the above, it is a paramount importance to have an in-depth knowledge on the morphological, physical and chemical characteristics of the soils of Itang special district and its surroundings which are selected as the site of the present study which is expected to provide baseline information for the future research efforts on soil fertility status of the area. 


\section{MATERIAL and METHODS}

\subsection{Description of the Study Area}

The site from which the research was conducted at the Gambella People National Regional State (GPNRS),(GPNRS), which is located at about $800 \mathrm{Km}$ south west of Addis Ababa.the research site found in west of the Gambella town in Itang special woreda . The average altitude of the research site is about 540 meters above sea level and average rain fall of the area is $1200 \mathrm{~mm}$

\subsubsection{Soil Sampling}

Twelve surface soil sample were purposively selected in three kebele in the Itang special woreda $(0-20 \mathrm{~cm}$ depth) than were thoroughly fixed on the based on field observation to represent the final respective land unit (LU) a total of twelve composite sample was collected on the cultivated land. The sampling sites were set and distributed in such a way that all the cultivated land LU (land units) was appropriately represented. The history of each sampling site including fertilization, slope, management practices, drainage, surface soil color, and others was record. Accordingly, pertinent data collected include cropping sequence, soil texture and soil management practices, drainage conditions, and other parameters, which are expected to affect soil fertility.

\subsubsection{Determination of Soil Physical Properties}

Soil textural analysis (particle size) were determined by hydrometer or Bouyoucus method after dispersion in a mixer with hexametaphosphate (Martin, 1993). Once the sand, silt, and clay separates was calculated in percent, the soil were assigned to a textural class based on the soil textural triangle (Rowell, 1994). Bulk density ( $\rho$ b) of each soil samples was analyzed using a volumetric cylinder and calculated by dividing the oven-dry mass at 105 ${ }^{0} \mathrm{C}$ by the volume of the oven- dried core. Particle density ( $\left.\rho s\right)$ by the pycinometer method as described by (Devis and Freitans, 1984),particle size distribution as described by (Gee and Bauder,1986) and then total porosity was estimated from the values bulk density and particle density using the equation (Rowell, 1994).

Total porosity $=(1-\rho b / \rho s) \times 100$

\subsubsection{Analysis of soil chemical properties}

The $\mathrm{pH}$ of the soil was measured using $\mathrm{pH}\left(\mathrm{H}_{2} \mathrm{O}\right)$ or $\mathrm{pH}(\mathrm{NaF})$ (Baruah and Barthakur, 1997). Soil organic matter was determined by using titrimetric methods and then its contents can be estimated from the organic carbon content by multiplying by 1.724 . Organic carbon contents were determined by the wet combustion or dichromate oxidation methods (Walkely and Black, 1934).Total nitrogen (N) content were determined using Kjeldhal method, available and total $\mathrm{P}$ was analyzed by using digestion of Bray method and colorimetrically using vanadomolybedate acid as an indicator respectively as described by (Black, 1945; Olsen and Sommers, 1982); while P retention index of different soils was determined by the single path analysis method (Wright, 1921). Water extractable P were determined by using deionized water or $0.01 \mathrm{M} \mathrm{CaCl} 2$ extraction procedure .Exchangeable basic cations $\left(\mathrm{Ca}^{2+}\right.$, $\mathrm{Mg}^{2+}$ and $\mathrm{Na}^{+}$) will be determined by saturating the soil samples with $1 \mathrm{~N} \mathrm{NH}_{4} \mathrm{OAc}$ solution. Then $\mathrm{Ca}^{2+}, \mathrm{Mg}^{2+}$ and $\mathrm{Na}^{+}$were determined by using atomic absorption spectrometry (AAS), while exchangeable $\mathrm{Na}^{+}$were measured by flame photometer from the same extract. Mineralogical clay fraction was determined by X-ray diffractions pectroscopy/ thermo gravimetric analysis. Carbonate content by Dietrich-Fehuligcalcimeter. Total exchangeable acidity was determined by saturating the soil samples with $1 \mathrm{M} \mathrm{KCl}$ solution and titrated with $0.02 \mathrm{M} \mathrm{HCl}$ as described by (Rowell, 1994). From the same extract, exchangeable $\mathrm{Al}^{3+}$ in the soil samples was titrated with a standard solution of $0.02 \mathrm{M} \mathrm{HCl}$. Then the exchangeable $\mathrm{H}^{+}$will be obtained by subtracting exchangeable $\mathrm{Al}^{3+}$ from total exchangeable acidity, which is $\mathrm{Al}$ and $\mathrm{H}$ ions (Rowell, 1994). Effective CEC capacity will be calculated by summation of exchangeable bases and exchangeable acidity. The percent base saturation of the soil samples was calculated from sum of the basic exchangeable cations $\left(\mathrm{Ca}^{2+}, \mathrm{Mg}^{2+}\right.$ and $\left.\mathrm{Na}^{+}\right)$as percentage of CEC (Baruah and Barthakur,1997).

\subsection{Statistical analysis}

Descriptive statistics with appropriate statistical tests, and critical value were used to analyze data and Districts were compared with each other by referring mean critical values for the selected physico-chemical properties of soils.

\section{Result and discussion \\ 4.1 soil physical properties}

The soil separates (sand, silt and clay fractions) were numerically different across the kebeles. The sand fraction was dominant on the Achwa and adong kebeles different in mekod kebeles, which was clay while the silt fractions was not dominant in the study area.

The clay percentage increased in mekod whilst the sand fraction also increased in Achwa and Adong district (Table 1). 
Table 1 Particle size distribution in the study area

\begin{tabular}{lllll}
\hline Districts & \multicolumn{2}{l}{ percent of soil particles } & \\
& Sand & silt & clay & textural class \\
\hline Achewa & 38 & 30 & 32 & Clay loam \\
Adong & 36 & 28 & 36 & Clay loam \\
Mekod & 28 & 27 & 45 & Clay \\
\hline
\end{tabular}

The highest clay percent observed in the soils of the mekod kebeles might be due to the degree of weathering tillage activities and the landscape of the area. The results of the particle size distribution of the study area indicated that the clay percentage decreased whereas the sand content increased with when we go to the river bank. The reason for sand particle in the two district could probable due to river deposition sand particle than other area.

\subsubsection{Soil bulk density and total porosity}

Bulk density varied from $1.3 \mathrm{~g} \mathrm{~cm}^{-3}$ (achewa), $1.23 \mathrm{~g} \mathrm{~cm}^{-3}$ (adong) to $1.2 \mathrm{~g} \mathrm{~cm}^{-3}$ (mekod) in study area. This reveals that the high amount of organic matter and well structure characteristics of resulted in low value of bulk density of soils. Hence, the increasing pattern in bulk densities with river bank districts could be related to a decrease in contents of organic matter and a presence of frequent cultivation. The highest bulk density in the abandoned land is attributed to the soil compaction and organic matter degradation as a result of continuous and intensive cultivation with heavy farm machinery. This result is in harmony with the research findings reported by Girma (1998). The highest bulk density noted under the frequent cultivation land could limit root growth, gas exchange and availability of less mobile essential plant nutrients, such as P and K (Dolan et al., 1992).

The total porosity of the soils, in general, varied with bulk density. Accordingly, total porosity increases as the bulk density decreases while it decreases as bulk density increases. Total porosity was relatively higher (54.7\%) in the Achwa followed by adong (53.6\%) and lowest total porosity was registered in Mekod (50.9\%) (Table 2).

Table 2. soil bulk density and total porosity in the study area

\begin{tabular}{llc}
\hline Districts & $\mathrm{BD}\left(\left(\mathrm{g} / \mathrm{cm}^{3}\right)\right)$ & $\mathrm{TP}(\%)$ \\
\hline Achewa & 1.3 & 50.9 \\
Adong & 1.23 & 53.6 \\
Mekod & 1.2 & 54.7 \\
\hline
\end{tabular}

$\mathrm{BD}=$ Bulk density; $\mathrm{TP}=$ total porosity

The higher values of total porosity corresponded to the higher amount of organic matter contents and lower bulk density values. The lowest and the highest total porosity were observed in the Mekod and Achewa and Adon districts, respectively, (Table 2). These results showed that land use systems slightly affect soil porosity because intensive cultivation without appropriate soil management results in organic matter degradation and soil compaction. The results obtained from this study are in agreement with the findings reported by other researchers (Singh et al., 1995; Maddonni et al., 1999).

The soil porosity varied from $54.7 \%$ to $50.9 \%$ in the study area soil. According to Brady and Weil (2002), ideal total pore space values, which are acceptable for crop production, are around $50 \%$. Hence, the soils of Achewa, Adong and Mekod districts have an acceptable range of total porosity values for crop production According to rating Beernaert (1990).

\subsection{Analysis of Soil Chemical Properties}

\subsubsection{Soil reaction $(\mathrm{pH})$ and electrical conductivity}

In all of study area, soil $\mathrm{pH}$ values measured in a suspension of $1: 2.5$ soil to water ratio $\left(\mathrm{pH}\right.$ in $\left.\mathrm{H}_{2} \mathrm{O}\right)$ were greater than the $\mathrm{pH}$ values measured in the same ratio of soil to $\mathrm{KCl}$ solution $(\mathrm{pH}$ in $\mathrm{KCl})$. The results on soil $\mathrm{pH}$ at different sites from three selected areas of Achewa, Adong and Mekod districts are presented in Table 3. The result revealed that soils were neutral in Achewa, and Adong whereas moderately alkaline in Mekod.

Table 3. soil $\mathrm{pH}$ and electrical conductivity in the study area

\begin{tabular}{lccc}
\hline Districts & $\mathrm{pH}\left(\mathrm{H}_{2} \mathrm{O}\right)$ & $\mathrm{pH}(\mathrm{KCl})$ & $\mathrm{EC}\left(\mathrm{dS} \mathrm{m}^{-1}\right)$ \\
\hline & & & \\
\hline Achewa & 6.95 & 5.45 & 0.28 \\
Adong & 6.86 & 5.12 & 0.24 \\
Mekod & 7.42 & 5.49 & 0.42 \\
\hline
\end{tabular}

$\mathrm{EC}=$ Electrical conductivity

The lowest $\mathrm{pH}$ value of under Achewa and Adong districts may be due to two major reasons. The first is the depletion of basic cations in crop harvest and drainage to streams in runoff generated from accelerated erosions. Secondly, it may be due to its highest microbial oxidation that produces organic acids, which provide $\mathrm{H}$ ions to the soil solution and thereby lowers soil pH. Anon (1993) also reported the increase in soil acidity due to measurement of $\mathrm{pH}$ in $\mathrm{KCl}$ solution showing the presence of high potential acidity. Considering the soil $\mathrm{pH}\left(\mathrm{H}_{2} \mathrm{O}\right)$, 
the soils in the present study area represented by Achewa and Adong were Neutral (6.95-6.86) and Mekod site were moderately alkaline as per the classification set by Tekalign (1991).

The electrical conductivity (EC) of soils in all districts was found to be well below unity (Table 4, 5). Considering the main effects of land use types, the highest $(0.42 \mathrm{dS} / \mathrm{m})$ and the lowest $(0.24 \mathrm{dS} / \mathrm{m})$ EC of the soils were obtained in Achewa and Mekod site respectively (Table3). The highest EC value at Achewa site might be due to its highest exchangeable Na content, whereas the lowest EC value at Mekod site can be associated with the loss of base forming cations $\left(\mathrm{Ca}^{+}\right.$and $\left.\mathrm{Mg}^{+}\right)$after deforestation and intensive cultivation. As indicated in (Table 3),

The highest EC was recorded in land unit $6(0.42 \mathrm{dS} \mathrm{m}-1)$ and the lowest $\mathrm{EC}$ was recorded in land unit $1(0.24$ dS m-1) were measured. According to the U.S Salinity Laboratory Staff (1954) classification, a soil is required to possess EC values greater than $4 \mathrm{dS} \mathrm{m}-1$ in order to qualify for saline and/or saline-sodic soil. Generally, the EC values measured in all districts in the study site indicated the concentration of soluble salts for below the levels at which growth and productivity of most agricultural crops are affected (Landon, 1991).Considering the surface soil which is explored by plant roots, all of the soils of the selected kebeles production and grazing fields considered in this study were classified as non-saline soils.

\subsubsection{Soil organic matter and total nitrogen}

Soil organic carbon was determined to estimate the amount of organic matter in the soil. Organic matter has an important influence on soil physical and chemical characteristics, soil fertility status, plant nutrition and biological activity in the soil (Brady and Weil, 2002).

The highest $(3.12 \%)$ and the lowest $(1.51 \%, 1.34)$ OM contents were recorded on Mekod, Achewa and Adong respectively. The highest OM content was recorded on the Mekod site which is apparently due to the contribution of vegetation cover of the area and less cultivation activity whereas the lower OM obtained in Achewa and Adong site might be frequent or twice cultivation per years leads to have low OM content in the study area.

Table 4. soil OM total nitrogen and available phosphorus in the study area

\begin{tabular}{lccc}
\hline Districts & OM $(\%)$ & TN N $(\%)$ & AV P $\left(\mathrm{mg} \mathrm{kg}^{-1}\right)$ \\
\hline \hline Achewa & & & \\
Adong & 1.51 & 0.164 & 13.72 \\
Mekod & 1.34 & 0.125 & 11.35 \\
\hline
\end{tabular}

$\mathrm{TN}=$ total nitrogen; Av.P $=$ available phosphorus

With respect to OM status of the study area, all the study area had low OM contents (Table 4) based on the nutrient ratings set by (Berhanu, 1980). Soil analysis in this study depicted that when the values of OM content increased, the contents of total $\mathrm{N}$ also increased and vice versa showing the direct relationship between them. Taye et al. (2003) also reported that the incorporation of high proportion of OM containing decomposed materials as a major component appreciably increased the organic carbon and total $\mathrm{N}$ contents. Based on the critical level given by (Berhanu, 1980) the Organic matter of the current study was satisfied low.

Total $\mathrm{N}$ content in different districts of soil from three selected areas are shown in Table 4. The percentage of total $\mathrm{N}$ content in Achewa, Adong and Mekod sites soil observed (0.164, 0.125 and $0.245 \%)$ respectively. The highest total N content was found at Mekod site, the lowest was at Achewa sites. According to Tekalign, (1991), the amount of total $\mathrm{N}$ in Achewa, Adong and Mekod soil were medium to high level (Table 4). These results were very close to the findings of Portach and Islam (1984) and SRDI (1996). It is apparent from the results that the N content decreased with the soil management (Hossain et al, 2003).Total $\mathrm{N}$ contents in these soils might be related to accelerated decomposition of organic matter in the tropical climate, less addition of organic matter, changes in cropping system, the quality and quantity of these elements in flooding water and variation in soil characteristics. Nitrogen content also decreased with decreasing organic matter content of soil. According to Havlin et al. (1999), soil total $\mathrm{N}$ contents of less than $0.15,0.15-0.25$ and greater than $0.25 \%$ are categorized as low, medium and high, respectively. Therefore, Mekod districts was found to have high contents of total $\mathrm{N}$ whereas, Achewa and Adong considered in the study had medium total $\mathrm{N}$ contents this could be attributed to the relatively medium OM contents of the respective site.

\subsubsection{Available phosphorus}

The highest and the lowest concentrations of available P were observed on Mekod and Achewa sites selected kebeles with mean values of 16.43 and $11.35 \mathrm{mg} \mathrm{kg}-1$, respectively. This variability could be the reflection of different soil management practices, that is, amount and type of organic residue add to the soil during different land use type, the length of fallowing period and crop rotation which varied from district to district. Birru (1999) reported that availability of $\mathrm{P}$ varied considerably with land use pattern, soil reaction, total $\mathrm{P}$ reserves and the particle size distributions of the soils.

The available P extracted by the Olsen method showed extremely high value (16.43 mg kg-1) in the Mekod districts (Table 4). This could be due to the relatively high organic matter content or high inherent $\mathrm{P}$ content of the parent material. Available Olsen's P is higher at the Mekod site and decreased with organic matter decrease in 
Adong and Achewa site of the study area.

Based on the ratings of Olsen et al (1954), the amounts of available $P$ in the study soils qualified high in all districts. Hence, $\mathrm{P}$ is not a limiting nutrient for crop production at three kebeles.

\subsubsection{Exchangeable bases}

Table 5 provides data on exchangeable basic cations percentage base saturation of the soils studied area. Exchangeable $\mathrm{Ca}$ and $\mathrm{Mg}$ were relatively predominant cations in the exchange sites of soil colloidal materials over the exchangeable $\mathrm{K}$ and $\mathrm{Na}$ in the order $\mathrm{Ca}>\mathrm{Mg}>\mathrm{K}>\mathrm{Na}$. The highest exchangeable $\mathrm{Ca}$ was obtained in Mekod $10.54 \mathrm{cmolc} \mathrm{kg}^{-1}$ followed by Achewa $8.51 \mathrm{cmolc} \mathrm{kg}^{-1}$ and the lowest mean values of exchangeable Ca were obtained in Adong districts7.25 cmolc kg-1 (table 5). Whereas $\mathrm{Mg}$ was 2.85, 1.87 and $1.32 \mathrm{cmolc}^{-1} \mathrm{~kg}^{-1} \mathrm{were}^{-1}$ obtained in Mekod, Achewa and Adong district respectively. The highest and the lowest contents of exchangeable $\mathrm{K}$ were observed in Mekod, Adong and Achewa with mean values of 1.45, 1.37and $1.25 \mathrm{cmolc} \mathrm{kg}^{-1}$, respectively, while exchangeable $\mathrm{Na}$ had its highest value was obtained in Adong 1.32 followed by Achewa 1.12 and lowest mean values of $0.87 \mathrm{cmolc} \mathrm{kg}^{-1}$ in Mekod respectively (Table 5). The distribution and the status of exchangeable bases in the study area can be displayed following the FAO (2006a) standard rating of exchangeable cations in the soil for the interpretation of cation exchange data (Appendix Table 5).

The highest concentrations of exchangeable bases in the Mekod and Achewa district could be probably due to the contribution of more OM by the virgin land and addition of more farmyard manure (FYM) to the cultivated land than the rest ones (Appendix Table 8). In agreement with this, several researchers reported that exchangeable bases were highly influenced by OM content of the soil maintained due to virgin land management or added to the soil of cultivated land (Taye et al., 2003; Heluf and Wakene, 2006).

Table 5. Exchangeable bases of the soil under three districts

\begin{tabular}{lrrrrcc}
\hline Districts & \multicolumn{6}{l}{ Exchangeable bases $(\mathrm{cmol}(+) / \mathrm{kg})$} \\
& $\mathrm{Ca}$ & $\mathrm{Mg}$ & $\mathrm{K}$ & $\mathrm{Na}$ & $\mathrm{TEB}$ & \\
\hline Achewa & 8.51 & 1.87 & 1.25 & 1.12 & 13.25 \\
Adong & 7.25 & 1.33 & 1.37 & 1.32 & 11.97 \\
Mekod & 10.54 & 2.85 & 1.45 & 0.87 & 16.43 \\
\hline
\end{tabular}

$\mathrm{TEB}=$ total Exchangeable bases

As per the nutrient ratings by FAO (2006a) for plant nutrition Mekod district fall under high exchangeable $\mathrm{Ca}$ and medium in the remaining two districts were observed in exchangeable $\mathrm{Ca}$. Exchangeable $\mathrm{Mg}$ were medium in all kebeles and very high in Exchangeable $\mathrm{K}$ were observed whereas Exchangeable Na could be rated high in all districts.

In terms of soil fertility, all exchangeable bases contents in the study area were relatively in a better status. In fact, there could be an increasing loss of all exchangeable cations in the study area due to continuous removal by crops without replenishment and vertical movement or leaching. Therefore, $\mathrm{K}$ content is adequate for the production of most crops and $\mathrm{K}$ deficiency would not be expected in the studied soils.

\section{REFERENCE}

Ahmed Hussein, 2002. Assessment of spatial variability of some physicochemical propertiesof soils under different elevations and land use systems in the western slopes of MountChilalo, Arsi. M.Sc. Thesis Submitted to the School of Graduate Studies, Alemaya University, Ethiopia. 111p.

Barauah, T.C. and H.P. Barthakulh, 1997. A textbook of soil analysis. Viskas Publishing House. New Delhi, India. $334 \mathrm{p}$.

Belay Simane, 2003. Integrated watershed management approach to sustainable land management (Experience of SARDP in East Gojjam and South Wollo). pp.127-136. In:

Bohn, H.L., McNeal, B.L. and O'Connor, G.A. 2001. Soil Chemistry. 3rd ed. John Wiley and Sons, Inc., USA.

Buol, S.W., F.D. Hole and R.J. McCracken, 1989. Soil genesis and classification, 3rd Ed.Ames, IA: The Iowa State University Press. Xiv, New Delhi. 446p.

Black, C.A., 1945. Methods of soil analysis part II. American Society of Agronomy, Madison, Wisconsin, USA. FAO, 2005. FAO's information system on water and agriculture. Available: http://www.fao.org/aquastat/countries/ethiopia.index.html

Foth, H.D., 1990. Fundamentals of soil science, 8th Ed. John Wiley and Sons, Inc., New York,USA. 360p.

Foth, H.D. and B.G. Ellis., 1997. Soil fertility, 2nd Ed. Lewis CRC Press LLC., USA. 290p

Hunt and Gilkes (1992); Cass (1999); Cresswell and Hamilton (2002); Geeveset al. (2007a).

Marshall and Holmes (1979); Greenland (1981); Jones (1983); Handreck and Black (1984);

Maddonni, G. A, S. Urricariet, C.M. Ghersa and R.S. Lavado. 1999. Assessing soil fertility in the rolling Pampa, using soil properties and maize characteristics. J. Agri. Res. Sci 91:280-286.

Mengel, K. and E.A. Kirkby, 1987. Principles of plant nutrition Panima Pub. Corporation, New Delhi, Bangalore, India. $687 \mathrm{p}$

Miller, R.W. and R.L. Donahue, 1995. Soils in our environment, 7th Ed. Prentice Hall Inc., Englewood Cliffs, 
New Jersey. 649p.

Murphy, H.F. 1968. A report on fertility status and other data on some soils of Ethiopia.Addis Ababa.

MengistuKuru, 2002. Tropical secondary forest management in Africa: Reality and perspectives. Ethiopia country paper. Presented at the workshop on tropical secondaryforest management in Africa: Realities and perspectives. Nairobi, Kenya. 9-13 December 2002.

MesfinAbebe. 1998. Nature and Management of Ethiopian Soils. Alemaya University of Agriculture.

Mokwunye, A.U., 1978. The role of in organic fertilizers in the chemical degradation of Nigerian Savannah soils. Samaru Conference Paper 14. Expert consultation on methodology for assessing soil degradation. FAO, Rome. 16p.

MulugetaLemenih, 2004. Effects of land use changes on soil quality and native flora degradation and restoration in the highlands of Ethiopia: Implication for sustainable land management. PhD Thesis Presented to Swedish University of Agricultural Sciences, Uppsala. 64p.

Nair, K.M. and G.S. Chamuah, 1993. Exchangeable aluminum in soils of Meghlaya and management of Al3+ related productive constraints. J. Indian Soc. Soil Sci. 4(1/2): 331-334.

Olsen, S.R. and L.E. Somers, 1982. Methods of soil analysis part 2A., R.H. Miller and D. R. Keeney (eds.). American Society of Agronomy, Madison. Wisconsin, USA

Sanchez, P.A., 1976. Properties and management of soils in the tropics. John Wiley and Sons, Inc., New York, USA. $618 \mathrm{p}$.

Saikh, H., Varadachari, C. and Ghosh, K. 1998b. Effects of deforestation and cultivation on soil CEC and contents of exchangeable bases. A case study in Simplipal National Park, India. Plant Soil 204: 67-75. 